\title{
Antioxidant Systems Response, Mineral Element Uptake and Safe Utilization of Polygonatum Sibiricum in Cadmium-Contaminated Soil
}

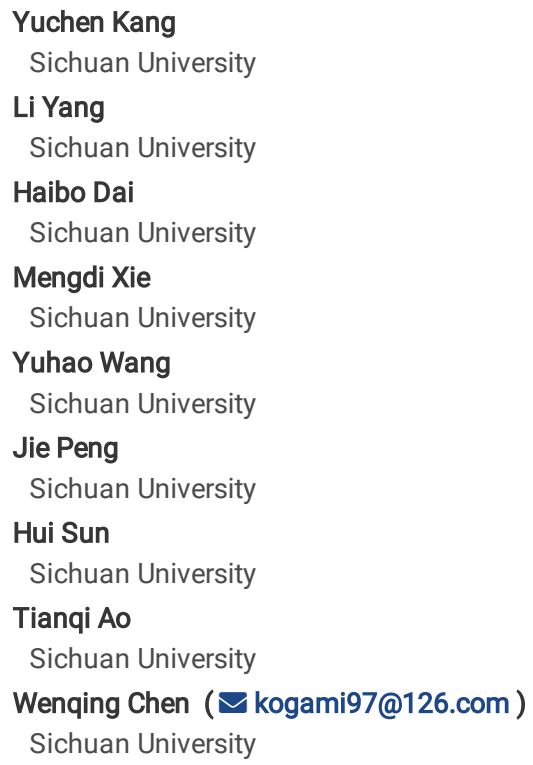




\section{Abstract}

Chinese herbal medicine is widely cultivated in southwest China where the soil cadmium (Cd) contamination of farmland is more serious than that in the whole of China. In this study, Polygonatum sibiricum were exposed to Cd at the concentrations of $\mathrm{e}^{-1}, \mathrm{e}^{0}, \mathrm{e}^{2}$, and $\mathrm{e}^{4} \mathrm{mg} \cdot \mathrm{kg}^{-1}$ for up to 30,60 , and 90 days and their physiological stress responses, $\mathrm{Cd}$ and mineral element uptake, antioxidant enzyme activities, and content changes of pharmaceutical ingredients (polysaccharides) were analyzed to decipher the feasibility of safety use in Cd contaminated soil. Results showed that the activity of antioxidant enzymes (SOD, POD, and CAT) of the aboveground part was enhanced in response to $\mathrm{Cd}$ stress after $90 \mathrm{~d}$. Compared with the control, the underground part mobilizes non-enzymatic systems to facilitate the synthesis of polysaccharides (PCP1, PCP2) with antioxidant properties to cope with Cd stress. Mineral elements (P, K, $\mathrm{Ca}, \mathrm{Mg}, \mathrm{Fe}, \mathrm{Cu}$, and $\mathrm{Zn}$ ) were significantly changed after $90 \mathrm{~d}$ of cultivation. In particular, the changes in iron and zinc contents were significantly correlated with the activities of SOD and POD. The soil Cd safety thresholds value for Polygonatum sibiricum is $\mathrm{e}^{0} \mathrm{mg} \cdot \mathrm{kg}^{-1}$, under which concentration the stimulation of Cd promotes polysaccharides synthesis and biomass growth.

\section{Introduction}

Southwest China is one of the main production areas of Chinese herbal medicine ${ }^{1}$, but the region has a long history of discharge of Cd-containing wastewater from zinc smelting, waste dumping, and the application of phosphate fertilizers with high Cd content, resulting in compound soil pollution of heavy metals is particularly prominent ${ }^{2}$. Among the various methods for remediation of contaminated soil, phytoremediation uses hyperaccumulation to extract heavy metals from the soil. Although this method is eco-friendly to eliminate heavy metals or other hazardous chemicals over other physical and chemical soil remediation techniques and does not cause secondary soil contamination ${ }^{3}$, it is difficult to promote phytoremediation techniques due to its long restoration cycle and the fact that the economic benefits of cultivated land cannot be guaranteed during the restoration cycle ${ }^{4}$. The purpose of agricultural land soil remediation is to ensure the safety of production and utilization of agricultural products ${ }^{5}$. Using the plants with high economic value and low heavy metal accumulation could break through the current dilemma of plant remediation and has great application potential.

In preliminary studies, we found that the Chinese herbal medicine Polygonatum sibiricum has the characteristic of low accumulation of Cd, and because it is rich in polysaccharides and other medicinal active components, it has a high added value and is an advantageous plant for the safe use of Cd-contaminated soil. For "low accumulation" cash crops, the antioxidant system is the main mechanism of resistance to heavy metal stress ${ }^{6}$. Heavy metals induce oxidative stress by generating free radicals and reactive oxygen species (ROS), which can interact with lipids, proteins, pigments, and nucleic acids, leading to lipid peroxidation and damage to cell membranes, impairing cellular physiology and the ability to adapt to the environment ${ }^{7}$. Harmful effects of the oxidative state of cells can be mitigated by enzymatic and non-enzymatic antioxidant effects in plants (Singh et al. 2006). Superoxide dismutase (SOD), catalase (CAT), and peroxidase (POD) are representative antioxidant enzymes that can scavenge excess ROS produced in plants ${ }^{8}$. SOD specifically dismutates superoxide anion into $\mathrm{H}_{2} \mathrm{O}_{2}$ and $\mathrm{O}_{2} . \mathrm{H}_{2} \mathrm{O}_{2}$ is destructive to many enzymes and can be degraded to $\mathrm{H}_{2} \mathrm{O}$ and $\mathrm{O}_{2}$ by CAT and POD ${ }^{9}$. Non-enzymatic antioxidant systems include $\beta$ - carotene, a - tocopherol, ascorbic acid, glutathione, flavonoids which have certain antioxidant value ${ }^{10}$. Numerous studies showing that polysaccharides especially heteropolysaccharides containing proteins and phenols also have antioxidant properties ${ }^{11-13}$. So, this research put polysaccharides, the main material to evaluate the economic value of Chinese herbal medicine ${ }^{14}$, into the non-enzymatic antioxidant system to conduct research and analysis.

Several studies have found that $\mathrm{Cd}$ has the potential to induce the synthesis of plant metabolites ${ }^{15}$, including certain pharmacologically active substances with antioxidant properties. Phyllanthus amarus under moderate chromium (Cr) stimulation produced more of the therapeutically active secondary metabolites - phyllanthin and hypophyllanthin ${ }^{16}$. A similar phenomenon occurs with another medicinal plant Vaccinium corymbosum and its antioxidant response is activated leading to an increase in phenolic compounds under the Cd stress ${ }^{17}$. However, this "incentive effect" is not costless. Medicinal plants may lose the ability to synthesize active ingredients at high concentrations of heavy metals. Seedlings of St. John's wort completely lose the ability to synthesize or accumulate hyperforin and the concentration of pseudohypericin and hypericin demonstrate a 15 to 20 -fold decrease ${ }^{18}$.

The mechanism of $\mathrm{Cd}$ tolerance in low-accumulating plants is rarely studied, and the response of their antioxidant active components to Cd is not clear yet, which calls into question how to ensure the safe use of low accumulation plants in Cd-contaminated soils. The plant mineral element uptake and tolerance for Cd vary between different plant species, plant growth phases, and soil Cd concentrations, hence it is necessary to systematically study the behavior of lowaccumulation plants under $\mathrm{Cd}$ stress. This study was specifically designed to (1) Determine the physiological stress responses and interaction between enzymatic and non-enzymatic antioxidant systems of Polygonatum sibiricum under Cd stress, (2) Analyse Cd and mineral element uptake situation and polysaccharides content change, (3) Present a soil Cd safety thresholds value for Polygonatum sibiricum growth.

\section{Materials And Methods}

\section{Plant material and growth conditions}

Experiments were conducted in soil-cultivated pots, and Polygonatum sibiricum was cultivated in wooden pots of $35 \mathrm{~cm} \times 35 \mathrm{~cm} \times 20 \mathrm{~cm}$, each with a soil mass of $15 \mathrm{~kg}$. The experimental soil for potted plants was collected from the Soil Contamination Remediation Project site in Mianzhu, Sichuan Province, with $20 \%$ (volumetric ratio) of humus and $5 \%$ (mass ratio) of sulfuric acid-type NPK fertilizer added to the soil (total Cd $0.12 \mathrm{mg} \mathrm{kg}^{-1}$, available Cd $0.029 \mathrm{mg} \cdot \mathrm{kg}^{-1}$, $\mathrm{pH}$ 7.4). The $\mathrm{Cd}$ in the experimental soil was added in the form of $\mathrm{CdCl}_{2}-2.5 \mathrm{H}_{2} \mathrm{O}$, and the designed soil Cd concentration gradients were $\mathrm{CK}-0$ mg $\cdot \mathrm{kg}^{-1}$, $\mathrm{e}^{-1}-0.37$ $\mathrm{mg} \cdot \mathrm{kg}^{-1}, \mathrm{e}^{0}-1 \mathrm{mg} \cdot \mathrm{kg}^{-1}, \mathrm{e}^{2}-7.39 \mathrm{mg} \cdot \mathrm{kg}^{-1}$, and $\mathrm{e}^{4}-54.60 \mathrm{mg} \cdot \mathrm{kg}^{-1}$. The 2-year-old seedlings of Polygonatum sibiricum were harvested from a traditional Chinese medicine cultivation base in Neijiang City, Sichuan Province. The collection of Polygonatum sibiricum complies with guidelines in Sichuan province and regulations in China. Plants were transplanted to pots after two weeks of soil equilibration then exposed to Cd stress. From each pot, three plants were

Page $2 / 12$ 
randomly collected after 30,60 , and $90 \mathrm{~d}$ of cultivation for the measurement of plant biomass, Cd content and mineral element uptake, and polysaccharide content, and the other three plants were collected for the measurement of the antioxidant system parameters. The roots of all plants were soaked in 0.01 mol. $\mathrm{L}^{-1}$ EDTA-2Na solution for 10 minutes to remove heavy metal ions and precipitates adsorbed on the surface.

\section{Cd and mineral element contents measurement}

Weigh the dried root, rhizome, stem, and leaf samples by $0.1 \mathrm{~g}$ using an analytical balance. Samples were placed in a crucible with $10 \mathrm{ml}$ of $\mathrm{HNO}_{3}$ and $2 \mathrm{ml}$ of $\mathrm{HClO}_{4}$ overnight, then digested on an electric plate until nearly dry and transferred to a $15 \mathrm{ml}$ centrifuge tube, which was fixed with $1 \% \mathrm{HNO}_{3}$ to $15 \mathrm{ml}$. Samples were analysed by inductively coupled plasma mass spectrometer (SHIMADZU ICPE-9000, JPN).

\section{Enzyme and polysaccharides antioxidant activity analysis}

The activity of SOD was determined according to the method of Jia, et al. ${ }^{19}$. The activity of CAT and POD was evaluated using the improved methods by Azevedo, et al. ${ }^{20}$. Using the pyrogallol autoxidation method according to Zhang, et al. ${ }^{21}$ to determine the antioxidant activity of polysaccharides.

\section{Extraction of Polysaccharides}

Using the method of graded extraction, $0.1 \mathrm{~g}$ of dried flavin was taken, and the residue was degreased by refluxing at $80^{\circ} \mathrm{C}$ for $24 \mathrm{~h}$. The residue was dried to obtain the defatted flavin sample. The sample was decocted in $10 \mathrm{~mL}$ of distilled water for $2 \mathrm{~h}$ each time, sonicated for $1 \mathrm{~h}$. The filtrate was filtered, combined, and transferred to a $50 \mathrm{ml}$ flask, where the liquid polysaccharide sample was PCP1. Taking the first stage of filtration and adding $0.1 \% \mathrm{NaOH}$ solution to extract, did the same steps as above and acquired the polysaccharide sample called PCP2. The second filtrate was extracted by adding $0.5 \% \mathrm{NaOH}$ solution, repeated the same steps as step 2 then obtained the polysaccharide sample named PCP3.

\section{Determination of polysaccharide content and molecular weight}

The glucose solution was dried to constant weight $\left(105^{\circ} \mathrm{C}\right), 33 \mathrm{mg}$ was taken and transferred to a $100 \mathrm{ml}$ flask. Add $0.2 \%$ anthrone - sulfuric acid solution in an ice water bath and slowly add the solution to the scale, mix well and let it cool for $10 \mathrm{~min}$ in a $100^{\circ} \mathrm{C}$-water bath, then immediately put it in an ice-water bath. The absorbance at $582 \mathrm{~nm}$ was measured by UV-Vis spectrophotometer (MAPADA UV-6100S, CHN) for 10 min. The polysaccharide liquid sample was treated as above, the absorbance was measured and the polysaccharide content was calculated against the standard curve. Polysaccharide molecular weight was determined by high-performance gel permeation chromatography according to Peng, et al. ${ }^{22}$.

\section{Statistical analysis}

Collection and aggregation of raw data using Excel and mapping using Origin 9.0 software. The biomass, Cd, and mineral element content, enzyme activities, and contents of polysaccharide data were subjected to correlation analysis, one-factor ANOVA, and Duncan multiple using GraphPad Prism 8.0 software.

\section{Results And Discussion Biomass and plants height}

The aboveground (stems and leaves) biomass and underground (roots and rhizomes) biomass showed opposite changes after $30 \mathrm{~d}$ cultivation (Fig.1A - B): the biomass of underground parts was smaller than that of the control group, while the biomass of aboveground showed a growth trend as the Cd concentration increases. But the negative influence of biomass occurred at $\mathrm{e}^{2}$ and $\mathrm{e}^{4}$ treatment after $90 \mathrm{~d}$ of cultivation. In comparison to CK treatment, the biomass of $\mathrm{e}^{2}$ and $\mathrm{e}^{4}$ groups were decreased by $40.22 \%$ and $63.90 \%$ (underground biomass), and by $33.27 \%$ and $53.85 \%$ (total biomass), respectively. However, compared with CK treatment, the biomass of underground part and total plants exposed to $\mathrm{e}^{-1}$ and $\mathrm{e}^{0}$ treatment was increased by $24.03 \%$ and $25.41 \%$ (underground biomass) and by $18.66 \%$ and $22.23 \%$ (total biomass), respectively, after $90 \mathrm{~d}$ of cultivation (Fig. 1B - C). The aboveground biomass (Fig.1A) and plant height (Fig.1D) showed a stable growth state at all Cd treatments after 90 days of cultivation. This phenomenon indicates that soil Cd at the concentration of $\mathrm{e}^{-1}$ and $\mathrm{e}^{0} \mathrm{mg} / \mathrm{kg}$ has positive effects on the growth of the whole plant and Polygonatum sibiricum exhibited good tolerance to Cd during persistent interaction with $\mathrm{Cd}$ in the soil.

\section{Cd content in different parts of plants}

Cd levels in plants increased in a dose-dependent manner (Fig.2). The highest Cd content in roots, rhizomes, stems, and leaves occurring in the $\mathrm{e}^{4}$ treatment after $90 \mathrm{~d}$ cultivation under which condition the plant $\mathrm{Cd}$ content was $239.04,16.38,12.84$, and $16.41 \mathrm{mg} / \mathrm{kg}$, respectively. The roots Cd content higher than other parts in all treatments and significantly increased with cultivation time (Fig.2A). The Cd content in the medicinal site rhizomes of $0.36\left(30 \mathrm{~d}, \mathrm{e}^{-1}\right), 0.43(30$ $\left.d, e^{0}\right), 0.33\left(60 d, e^{-1}\right), 0.64\left(60 d, e^{0}\right), 0.20\left(90 d, e^{-1}\right), 0.69\left(90 \mathrm{~d}, e^{0}\right) \mathrm{mg}^{\circ} \mathrm{kg}^{-1}$, respectively (Fig.2B), was lower than the limit value of Cd content in Pharmacopoeia of the People's Republic of China but it fails to meet the requirements in $\mathrm{e}^{2}$ and $\mathrm{e}^{4}$ treatment due to an excessive soil Cd concentration. After $90 \mathrm{~d}$ of cultivation, the $\mathrm{Cd}$ content in stems and leaves was higher than $30 \mathrm{~d}$ of cultivation and increased as Cd levels increased (Fig.2C - D). Previous studies 
have also shown that the roots could be the highest $\mathrm{Cd}$ content parts of plants ${ }^{23,24}$ because roots are the primary organs in the response to Cd stress in soil and $\mathrm{Cd}$ can complex with proteins, cellulose or pectates, or insoluble $\mathrm{Cd}$-phosphate in the root cell wall ${ }^{25}$. This characteristic of $\mathrm{Cd}$ uptake of roots is consistent with the accumulation of heavy metals in root-hoarding plants. Root-hoarding plants store heavy metals mainly in the roots, and only a small amount of heavy metal is transferred to the ground that reduces damage to the photosynthetic, respiratory, and reproductive systems ${ }^{26}$. This "root-retention" characteristic of Polygonatum sibiricum is beneficial to improve survivability in Cd-contaminated soil and ensure the safety of medicinal parts.

\section{Antioxidant enzyme system}

Aboveground and underground parts showed different patterns of SOD and POD activity (Fig.3A - B). For the aboveground part after $30 \mathrm{~d}$ of cultivation, SOD activity increased with $\mathrm{Cd}$ levels raise, and it was maximum high at $\mathrm{e}^{4}$ treatment, which was $52.17 \%$ higher than that of the control group. After $90 \mathrm{~d}$ of cultivation, the activity of SOD could attach to $1.47,1.45$, and1.27 times higher than $C K$ in the $\mathrm{e}^{-1}, \mathrm{e}^{0}, \mathrm{e}^{2}$ treatment, respectively. However, for the underground parts, the high Cd treatment shows lower SOD activity through the full cultivation time. Furthermore, the correlation coefficients revealed that there was a negative correlation between the underground parts $C d$ content and SOD activity $(r=-0.5538, p<0.05)$ (Table 1$)$, indicating that the response of SOD to Cd is suppressed slightly. The POD activity of aboveground/underground parts increased/decreased as the Cd levels increased and the maximum and minimum activity both occurred in $\mathrm{e}^{4}$ treatment after $30 \mathrm{~d}$ of cultivation. After $90 \mathrm{~d}$ of cultivation, the POD activity was 6.41 and 6.47 times higher than CK in $\mathrm{e}^{2}$ and $\mathrm{e}^{4}$ treatment. As shown in Fig. 3C, the CAT activities increased as the cultivation times increased, and the aboveground enzyme activity was higher than that of the underground part. Only after $60 \mathrm{~d}$ of cultivation, $\mathrm{Cd}$ demonstrates a stimulating effect on enzyme activity.

Typically, studies of plant antioxidant enzyme activity focused on the aboveground part, with a few experiments considering the differences between aboveground and underground antioxidant enzymes. The aboveground SOD activity of Polygonatum sibiricum was similar to that of most plants, but the SOD activity of the underground parts was lower than that of the control group under a higher Cd level $\left(\mathrm{e}^{0}, \mathrm{e}^{2}\right.$, and $\mathrm{e}^{4}$ treatment), which showed a difference. The results showed that the response thresholds of SOD, POD, CAT to Cd stimulation are different, and the correlation between the effect of Cd stimulation on the activities of antioxidant enzymes and the concentration of $\mathrm{Cd}$ in plants is always variant. Some researchers suggest that $\mathrm{Cd}$ inhibits the activity of antioxidant enzymes ${ }^{27}$, and some show that Cd stress could activate antioxidant enzymes ${ }^{28}$, even in some study, the aboveground and underground parts of the same plant have different responses to antioxidant enzyme activity ${ }^{29}$. At the same time, the changes of CAT and POD activity are not uniform, which indicates antioxidant enzyme activities and plant species are also related, exploiting different tolerance behaviours to alleviate Cd-induced oxidative stress.

\section{mineral element uptake}

The changing macronutrients $(\mathrm{P}, \mathrm{K}, \mathrm{Ca}$, and $\mathrm{Mg})$ in Polygonatum sibiricum are shown in Fig. 4A-D in response to the Cd stress. Phosphorus $(\mathrm{P})$ is an essential macronutrient that not only supports plant growth but also reduces the toxicity of cadmium by chelating or forming complexes with cadmium in plants, thereby reducing the damage to cell function caused by $\mathrm{Cd}^{30}$. In $\mathrm{e}^{-1}$ and $\mathrm{e}^{0}$ treatment, the $\mathrm{P}$ content was increased by $27.6 \%, 17.7 \%$, respectively, and $27.9 \%$, $39.32 \%$ respectively, after 30 and $60 \mathrm{~d}$ of cultivation compared to CK treatment. But under higher Cd stress $\left(\mathrm{e}^{2}\right.$ and $\left.\mathrm{e}^{4}\right)$ and long-term Cd stress of $90 \mathrm{~d}$, the $\mathrm{P}$ content was declined. This indicates that $\mathrm{Cd}$ can affect the uptake and accumulation of elemental $\mathrm{P}$ in Polygonatum sibiricum while $\mathrm{P}$ was described as having no effect on Cd uptake ${ }^{31}$.

Potassium(K) is the most abundant inorganic cation in plant cells (Benito et al. 2014). The $\mathrm{K}$ content in all treatments reached maximum value after $90 \mathrm{~d}$ of cultivation and, to varying degrees, could find a facilitative effect of $\mathrm{Cd}$ on $\mathrm{K}$ uptake except for the $\mathrm{e}^{4}$ treatment. The phenomenon might be related to the ability of $\mathrm{Cd}$ can increase the influx of $\mathrm{K}^{+}$ions by binding to $\mathrm{K}$ channels and opening them permanently ${ }^{32,33}$ while the complexation of ATP with $\mathrm{CD}$ proved that the absorption of $\mathrm{K}$ decreased and the available energy of membrane transport system decreased lead to disruption in the plasma membrane and caused the decline of $\mathrm{K}$ under $\mathrm{Cd}$ concentrations as a result of $\mathrm{K}$ leakage ${ }^{34}$.

Calcium (Ca) content was significantly promoted by Cd stress and increased by $140.03 \%, 101.25 \%, 27.11 \%$, and $38.35 \%$, respectively, in $\mathrm{e}^{-1}$, $\mathrm{e}^{0}, \mathrm{e}^{2}$, and $\mathrm{e}^{4}$ treatment after $60 \mathrm{~d}$ of cultivation. However, it was altered after $90 \mathrm{~d}$ of cultivation that Ca uptake was inhibited except $\mathrm{e}^{2}$ treatment. It has been reported that the Ca content in plants growing in Cd-contaminated solutions is reduced in different plants, possibly due to competition between $\mathrm{Cd}^{2+}$ and divalent cations during the absorption process ${ }^{35,36}$. But researches also showed that the action of $\mathrm{Cd}$ on Ca channels and transporter proteins lead to an increase in their transcription and translation, thus allowing greater Ca uptake and compensating for the blocking effect of Ca channels ${ }^{32}$. Thus, it can be seen that the interaction between $\mathrm{Ca}$ and $\mathrm{Cd}$ is adjusted according to the concentration of $\mathrm{Cd}$ and the duration of stress.

Magnesium (Mg) content decreased progressively with increasing plant cultivation time. In particular, compared with CK treatment after $90 \mathrm{~d}$ of cultivation, the Mg content declined by $71.46 \%, 45.05 \%, 66.26 \%$, and $38.99 \%$, respectively, in $\mathrm{e}^{-1}, \mathrm{e}^{0}, \mathrm{e}^{2}$, and $\mathrm{e}^{4}$ treatment. Pearson correlation coefficients between Mg contents and POD activity $(r=-0.5664, p<0.05)$ (Table 1$)$ indicated that the toxicity of Cd can promote the reduction of Mg which in turn affected the enzyme activity that $\mathrm{Mg}$ was a master activator of more than 300 enzymes ${ }^{37}$.

In this study, significant positive relationships were found between Cd content and Iron (Fe), Copper (Cu) and Zinc (Zn) content ( $r=0.7613,0.6337$ and 0.6320 , $p<0.05)$. Moreover, Fe, $\mathrm{Cu}$ and $\mathrm{Zn}$ content also correlated strongly with each other ( $r=0.6654,0.8199$ and $0.5671, p<0.05)$. After $90 \mathrm{~d}$ of cultivation, Fe, Cu, and $\mathrm{Zn}$ content increased under high Cd treatment compared with CK treatment (Fig 4E - G). It had also been shown that Fe and Zn content were strongly negatively correlated with SOD and POD activity $(r=-0.7291$ and $-0.5768,-0.6349$ and $-0.7501, p<0.05)$ and PCP1 and TPCP content $(r=-0.6956$ and -0.6445 , -0.7306 and $-0.6420, p<0.05)$. Fe, $\mathrm{Cu}$, and $\mathrm{Zn}$ have in the formation of enzymes that are crucial in the plant antioxidative mechanisms and Cd have

Page $4 / 12$ 
replacement/displacement of $\mathrm{Fe}, \mathrm{Cu}$, and $\mathrm{Zn}$ in enzymes or other molecules by different macromolecules. Thus, this effect may plunge regulatory mechanisms into a state of $\mathrm{Fe} / \mathrm{Cu} / \mathrm{Zn}$ deficient, leading to an increment in their uptake as an over compensatory mechanism ${ }^{38}$. The toxicity of Cd to plants disrupts the uptake and distribution of mineral elements in tissues, leading to mineral deficiencies, overcompensation, or imbalance, which in turn affects the activity of related enzymes and causes damage to the plant's antioxidant system.

\section{Polysaccharide content and its antioxidant properties}

Compared to the control group, Polygonatum sibiricum was appropriately stimulated to increase polysaccharide content in all treatments through $30 \mathrm{~d}$ of cultivation, while at a higher Cd level, this stimulatory effect was reduced as evidenced by the inhibition of polysaccharide synthesis at $\mathrm{e}^{4}$ treatment instead of after 60 and $90 \mathrm{~d}$ of cultivation (Fig.5). However, total polysaccharides after $90 \mathrm{~d}$ of cultivation decreased by $8.45 \%, 20.25 \%, 46.12 \%$, and $50.77 \%$, respectively, compared with $30 \mathrm{~d}$ of cultivation. But it's worth noting that the control group decreased by $16.31 \%$ as well. The depletion of polysaccharides in rhizomes is presumed to be due, on the one hand, to the growing period and, on the other hand, to excessive Cd stress. Among them, the Cd stress showed the best promotion effect on polysaccharides synthesis at $\mathrm{e}^{0}$ treatment.

The antioxidant activity of the three polysaccharides in the rhizome of Polygonatum sibiricum was in the order of PCP1> PCP2> PCP3 (Table 2). The polysaccharide from the first step and second step showed the scavenging rate of superoxide anions at $5.61 \%$ and $3.06 \%$, respectively. The polysaccharides from the last step did not show antioxidant activity. Evidence had proved that the molecular weight distributions of polysaccharides had a great influence on their biological activities ${ }^{39}$. PCP1 has the lowest molecular weight with the best performance in scavenging superoxide radicals which could find a similar result that high molecular weight polysaccharides are less active than low molecular weight ${ }^{40}$.

Not only are sugars a source of nutrients and a component of the structural parts of plants, but more and more researches are now showing that sugars play an important role in plant stress tolerance ${ }^{41,42}$. Most of the polysaccharides in plants are heteropolysaccharides, which not only consist of various kinds of monosaccharides but also proteins, phenols, etc. The antioxidant functional groups of these substances can significantly enhance the antioxidant properties of plant polysaccharides. Therefore, the role of polysaccharides as non-enzymatic antioxidants in plant stress tolerance cannot be ignored. From correlation analysis (Table.2), there was a significant positive correlation $(r=0.8394, p<0.01)$ between polysaccharides and POD activity. Fewer studies have investigated the role of polysaccharides as part of a non-enzymatic antioxidant system in plant resilience, but several studies have shown that plant polysaccharides have antioxidant effects and mitigate heavy metal toxicity $43-45$.

\section{Conclusion}

This study found that the soil Cd safety threshold concentration is $\mathrm{e}^{0} \mathrm{mg} \cdot \mathrm{kg}^{-1}$. In $\mathrm{e}^{-1}$ and $\mathrm{e}^{0}$ treatment, the Cd content of Polygonatum sibiricum rhizome meets the consumption standard of heavy metals in Chinese herbal medicine stipulated in the Pharmacopoeia of the People's Republic of China, and the biomass of Polygonatum sibiricum increased showing a Cd tolerance and utilization safety. For the aboveground part of Polygonatum sibiricum, SOD and CAT activity are increased to cope with ROS generated by oxidative stress at higher Cd concentrations. For the underground part, enzymatic and non-enzymatic systems act synergistically which embodies an enhancement in antioxidant enzyme activity and an increase in polysaccharide synthesis at lower Cd treatment. Both enzymatic and non-enzymatic systems are partially inhibited at higher Cd treatment. The stimulatory effect of Cd changes the mineral element uptake of Polygonatum sibiricum especially in high Cd treatment and caused an influence on the enzyme system of plants. In conclusion, the safe utilization of Polygonatum sibiricum can be guaranteed, and it has high application potential in soil remediation areas with lower Cd contamination.

\section{Declarations}

\section{Declaration of interest statement}

The authors declare that they have no competing interests.

\section{Ethics approval and consent to participate}

Not applicable

\section{Consent for publication}

Not applicable

\section{Availability of data and materials}

The datasets used and/or analyzed during the current study are available from the corresponding author on reasonable request.

\section{Code availability}

Not applicable

\section{Competing interests}

The authors declare that they have no competing interests. 


\section{Statement in the collection of plant material}

The collection of Polygonatum sibiricum is in compliance with guidelines in Sichuan province and regulations in China. All collection was done with the permission of the relevant regulatory governing bodies and with reference to the relevant legislation.

\section{Funding}

This work was supported by the Project of Major Science and Technology of Sichuan Province [grant number 2018SZDZX0028]

\section{Authors' contributions}

All authors contributed to the study's conception and design. Conceptualization: W C, Writing - review \& editing: T A, Supervision: H S, Formal analysis: L Y, Investigation: M X, Methodology: J P, Experiment: H D, Data collection: Y W, Writing - original draft: Y K. All authors read and approved the final manuscript.

\section{Acknowledgments}

This work was supported by the Project of Major Science and Technology of Sichuan province [grant number 2018SZDZX0028]. Thanks to workers for the construction of experimental sites and transportation of experimental soils and all the people who have helped with the completion of the manuscript. We are grateful to Yu He, a Ph.D. candidate from Georgia Institute of Technology (USA), for the English improvement of our manuscript.

\section{References}

1. Kang, C.-Z. et al. Pattern of ecological planting for Chinese materia medica based on regional distribution. Zhongguo Zhong yao za zhi = Zhongguo zhongyao zazhi = China journal of Chinese materia medica 45, 1982-1989, doi:10.19540/j.cnki.cjcmm.20200302.103 (2020).

2. Luo, Y. M. \& Teng, Y. Regional Difference in Soil Pollution and Strategy of Soil Zonal Governance and Remediation in China. Bulletin of Chinese Academy of ences 33, 145-152 (2018).

3. Kanwar, V. S., Sharma, A., Srivastav, A. L. \& Rani, L. Phytoremediation of toxic metals present in soil and water environment: a critical review. Environmental Science and Pollution Research 27, 44835-44860, doi:10.1007/s11356-020-10713-3 (2020).

4. Suresh, B. \& Ravishankar, G. A. Phytoremediation-A Novel and Promising Approach for Environmental Clean-up. Critical Reviews in Biotechnology 24, 97124, doi:10.1080/07388550490493627 (2004).

5. Zhang, T. L. \& Wang, X. X. Prevention and Remediation of Soil Contamination to Strengthen the Fo undation for Green and High-Quality Agricultural Development in China. Acta Pedologica Sinica 56, 251-258 (2019).

6. Maleki, M., Ghorbanpour, M. \& Kariman, K. Physiological and antioxidative responses of medicinal plants exposed to heavy metals stress. Plant Gene 11, 247-254, doi:10.1016/j.plgene.2017.04.006 (2017).

7. Dissanayake, N. M., Current, K. M. \& Obare, S. O. Mutagenic Effects of Iron Oxide Nanoparticles on Biological Cells. Int. J. Mol. Sci. 16, 23482-23516, doi:10.3390/ijms161023482 (2015).

8. Mittler, R. Oxidative stress, antioxidants and stress tolerance. TRENDS in Plant Science 7, 405-410 (2002).

9. Tewari, R. K., Kumar, P. \& Sharma, P. N. Antioxidant responses to enhanced generation of superoxide anion radical and hydrogen peroxide in the copperstressed mulberry plants. Planta 223, 1145-1153, doi:10.1007/s00425-005-0160-5 (2006).

10. Wu, F., Zhang, G., Dominy, P., Wu, H. \& Bachir, D. M. L. Differences in yield components and kernel Cd accumulation in response to Cd toxicity in four barley genotypes. Chemosphere 70, 83-92, doi:10.1016/j.chemosphere.2007.06.051 (2007).

11. Ross, K. A., Godfrey, D. \& Fukumoto, L. The chemical composition, antioxidant activity and a-glucosidase inhibitory activity of water-extractable polysaccharide conjugates from northern Manitoba lingonberry. Cogent Food \& Agriculture 1, 1109781, doi:10.1080/23311932.2015.1109781 (2015).

12. Liu, J. et al. Isolation, structural characterization and bioactivities of naturally occurring polysaccharide-polyphenolic conjugates from medicinal plants-A reivew. Int. J. Biol. Macromol. 107, 2242-2250, doi:10.1016/j.ijbiomac.2017.10.097 (2018).

13. Fu, J. L. et al. A mechanism by which Astragalus polysaccharide protects against RoS toxicity through inhibiting the protein dephosphorylation of boar sperm preserved at 4 degrees C. J. Cell. Physiol. 233, 5267-5280, doi:10.1002/jcp.26321 (2018).

14. Kang, C.-Z., Zhou, T., Jiang, W.-K., Huang, L.-Q. \& Guo, L.-P. Research model on commodity specification standard of radix Chinese materia medica. Zhongguo Zhong yao za zhi = Zhongguo zhongyao zazhi = China journal of Chinese materia medica 41, 769-775, doi:10.4268/cjcmm20160503 (2016).

15. Xie, M. D. et al. Metabolomics reveals the "Invisible" detoxification mechanisms of Amaranthus hypochondriacus at three ages upon exposure to different levels of cadmium. Ecotox. Environ. Safe. 195, 9, doi:10.1016/j.ecoenv.2020.110520 (2020).

16. Rai, V. \& Mehrotra, S. Chromium-induced changes in ultramorphology and secondary metabolites of Phyllanthus amarus Schum \& Thonn. - an hepatoprotective plant. Environmental Monitoring and Assessment 147, 307-315, doi:10.1007/s10661-007-0122-4 (2008).

17. Manquian-Cerda, K. et al. Effect of cadmium on phenolic compounds, antioxidant enzyme activity and oxidative stress in blueberry (Vaccinium corymbosum L.) plantlets grown in vitro. Ecotox. Environ. Safe. 133, 316-326, doi:10.1016/j.ecoenv.2016.07.029 (2016).

18. Murch, S. J., Haq, K., Rupasinghe, H. P. V. \& Saxena, P. K. Nickel contamination affects growth and secondary metabolite composition of St. John's wort (Hypericum perforatum L.). Environmental and Experimental Botany 49, 251-257, doi:10.1016/s0098-8472(02)00090-4 (2003).

19. Jia, X., Zhao, Y. H., Liu, T. \& He, Y. H. Leaf defense system of Robinia pseudoacacia L. seedlings exposed to 3 years of elevated atmospheric CO2 and Cdcontaminated soils. Science of the Total Environment 605, 48-57, doi:10.1016/j.scitotenv.2017.06.172 (2017). 
20. Azevedo, R. A., Alas, R. M., Smith, R. J. \& Lea, P. J. Response of antioxidant enzymes to transfer from elevated carbon dioxide to air and ozone fumigation, in the leaves and roots of wild-type and a catalase-deficient mutant of barley. Physiol. Plant. 104, 280-292, doi:10.1034/j.1399-3054.1998.1040217.x (1998).

21. Zhang, Q. A., Wang, X., Song, Y., Fan, X. H. \& Martin, J. F. G. Optimization of Pyrogallol Autoxidation Conditions and Its Application in Evaluation of Superoxide Anion Radical Scavenging Capacity for Four Antioxidants. J. AOAC Int. 99, 504-511, doi:10.5740/jaoacint.15-0223 (2016).

22. Peng, Q., Li, M., Xue, F. \& Liu, H. J. Structure and immunobiological activity of a new polysaccharide from Bletilla striata. Carbohydr. Polym. 107, 119-123, doi:10.1016/j.carbpol.2014.02.042 (2014).

23. Jiang, Y. et al. Overexpression of SmZIP plays important roles in Cd accumulation and translocation, subcellular distribution, and chemical forms in transgenic tobacco under Cd stress. Ecotox. Environ. Safe. 214, 112097-112097, doi:10.1016/j.ecoenv.2021.112097 (2021).

24. Rui, H., Chen, C., Zhang, X., Shen, Z. \& Zhang, F. Cd-induced oxidative stress and lignification in the roots of two Vicia sativa L. varieties with different Cd tolerances. Journal of Hazardous Materials 301, 304-313, doi:10.1016/j.jhazmat.2015.08.052 (2016).

25. Huang, R. Z., Jiang, Y. B., Jia, C. H., Jiang, S. M. \& Yan, X. P. Subcellular distribution and chemical forms of cadmium in Morus alba L. Int. J. Phytoremediat. 20, 448-453, doi:10.1080/15226514.2017.1365344 (2018).

26. Lei, M., Yuo, Q. L., Chen, T. B., Huang, Z. C. \& Liao, X. Y. Heavy metal concentrations in soils and plants around Shizuyuan mining area of Hunan Province. Acta Ecologica Sinica, 1146-1151 (2005).

27. Nahakpam, S. \& Shah, K. Expression of key antioxidant enzymes under combined effect of heat and cadmium toxicity in growing rice seedlings. Plant Growth Regulation 63, 23-35, doi:10.1007/s10725-010-9508-3 (2011).

28. Dinakar, N., Nagajyothi, P. C., Suresh, S., Udaykiran, Y. \& Damodharam, T. Phytotoxicity of cadmium on protein, proline and antioxidant enzyme activities in growing Arachis hypogaea L. seedlings. J. Environ. Sci. 20, 199-206, doi:10.1016/s1001-0742(08)60032-7 (2008).

29. Zoufan, P., Jalali, R., Hassibi, P., Neisi, E. \& Rastegarzadeh, S. Evaluation of antioxidant bioindicators and growth responses in Malva parviflora L. exposed to cadmium. Physiol. Mol. Biol. Plants 24, 1005-1016, doi:10.1007/s12298-018-0596-2 (2018).

30. Gomes, M. P., Soares, A. M. \& Garcia, Q. S. Phosphorous and sulfur nutrition modulate antioxidant defenses in Myracrodruom urundeuva plants exposed to arsenic. Journal of Hazardous Materials 276, 97-104, doi:10.1016/j.jhazmat.2014.05.020 (2014).

31. Zhong, W. L., Li, J. T., Chen, Y. T., Shu, W. S. \& Liao, B. A study on the effects of lead, cadmium and phosphorus on the lead and cadmium uptake efficacy of Viola baoshanensis inoculated with arbuscular mycorrhizal fungi. J. Environ. Monit. 14, 2497-2504, doi:10.1039/c2em30333g (2012).

32. De la Rosa, G. et al. Production of low-molecular weight thiols as a response to cadmium uptake by tumbleweed (Salsola kah). Plant Physiology and Biochemistry 43, 491-498, doi:10.1016/j.plaphy.2005.03.013 (2005).

33. Mourato, M. et al. in Cadmium Toxicity and Tolerance in Plants (eds Mirza Hasanuzzaman, Majeti Narasimha Vara Prasad, \& Masayuki Fujita) 327-348 (Academic Press, 2019).

34. Ghnaya, T. et al. Cadmium effects on growth and mineral nutrition of two halophytes: Sesuvium portulacastrum and Mesembryanthemum crystallinum. J. Plant Physiol. 162, 1133-1140, doi:10.1016/j.jplph.2004.11.011 (2005).

35. Walker, W. M., Miller, J. E. \& Hassett, J. J. EFFECT OF LEAD AND CADMIUM UPON CALCIUM, MAGNESIUM, POTASSIUM, AND PHOSPHORUS CONCENTRATION IN YOUNG CORN PLANTS. Soil Science 124, 145-151, doi:10.1097/00010694-197709000-00004 (1977).

36. Paoli, L., Vannini, A., Monaci, F. \& Loppi, S. Competition between heavy metal ions for binding sites in lichens: Implications for biomonitoring studies. Chemosphere 199, 655-660, doi:10.1016/j.chemosphere.2018.02.066 (2018).

37. Bose, J., Babourina, O. \& Rengel, Z. Role of magnesium in alleviation of aluminium toxicity in plants. J. Exp. Bot. 62, 2251-2264, doi:10.1093/jxb/erq456 (2011).

38. Assuncao, A. G. L., Bleeker, P., ten Bookum, W. M., Vooijs, R. \& Schat, H. Intraspecific variation of metal preference patterns for hyperaccumulation in Thlaspi caerulescens: evidence from binary metal exposures. Plant Soil 303, 289-299, doi:10.1007/s11104-007-9508-x (2008).

39. Sheng, J. W. \& Sun, Y. L. Antioxidant properties of different molecular weight polysaccharides from Athyrium multidentatum (Doll.) Ching. Carbohydr. Polym. 108, 41-45, doi:10.1016/j.carbpol.2014.03.011 (2014).

40. Wu, Y.-T. et al. Purification, characterization and antioxidant activity of polysaccharides from Porphyra haitanensis. Int. J. Biol. Macromol. 165, 2116-2125, doi:10.1016/j.ijbiomac.2020.10.053 (2020).

41. Pirselova, B. \& Matusikova, I. Callose: the plant cell wall polysaccharide with multiple biological functions. Acta Physiol. Plant. 35, 635-644, doi:10.1007/s11738-012-1103-y (2013).

42. Xu, S. S., Lin, S. Z. \& Lai, Z. X. Cadmium impairs iron homeostasis in Arabidopsis thaliana by increasing the polysaccharide contents and the iron-binding capacity of root cell walls. Plant Soil 392, 71-85, doi:10.1007/s11104-015-2443-3 (2015).

43. Sun, H. Q. et al. Function and mechanism of polysaccharide on enhancing tolerance of Trichoderma asperellum under Pb2+ stress. Int. J. Biol. Macromol. 151, 509-518, doi:10.1016/j.ijbiomac.2020.02.207 (2020).

44. Li, S. P. et al. A polysaccharide isolated from Cordyceps sinensis, a traditional Chinese medicine, protects PC12 cells against hydrogen peroxide-induced injury. Life Sci. 73, 2503-2513, doi:10.1016/s0024-3205(03)00652-0 (2003).

45. Li, J. J. et al. Biochemical changes of polysaccharides and proteins within EPS under Pb (II) stress in Rhodotorula mucilaginosa. Ecotox. Environ. Safe. 174, 484-490, doi:10.1016/j.ecoenv.2019.03.004 (2019).

\section{Tables}

Page $7 / 12$ 
Table 1 Pearson correlation coefficients between Cd content, enzyme activity, polysaccharides content, and mineral element content of Polygonatum sibiricum

\begin{tabular}{|c|c|c|c|c|c|c|c|c|c|c|c|c|c|}
\hline & $\mathrm{Cd}$ & SOD & POD & CAT & PCP1 & PCP2 & PCP3 & TPCP & $P$ & $\mathrm{~K}$ & $\mathrm{Ca}$ & $\mathrm{Mg}$ & $\mathrm{Fe}$ \\
\hline $\mathrm{Cd}$ & 1.0000 & & & & & & & & & & & & \\
\hline SOD & $-0.5538^{*}$ & 1.0000 & & & & & & & & & & & \\
\hline POD & -0.4012 & 0.0862 & 1.0000 & & & & & & & & & & \\
\hline CAT & -0.0138 & -0.0610 & 0.1784 & 1.0000 & & & & & & & & & \\
\hline PCP1 & -0.4740 & 0.1002 & $0.8394^{\star}$ & 0.2836 & 1.0000 & & & & & & & & \\
\hline PCP2 & -0.0638 & 0.1568 & -0.2821 & 0.1527 & -0.3403 & 1.0000 & & & & & & & \\
\hline PCP3 & -0.2189 & 0.2496 & 0.3131 & 0.3440 & 0.2144 & $0.7041^{*}$ & 1.0000 & & & & & & \\
\hline TPCP & -0.5100 & 0.1595 & $0.8231^{*}$ & 0.3528 & $0.9595^{\star}$ & -0.0693 & 0.4666 & 1.0000 & & & & & \\
\hline $\mathrm{P}$ & -0.1112 & 0.4149 & -0.3026 & 0.1343 & -0.1328 & 0.4595 & 0.2219 & -0.0214 & 1.0000 & & & & \\
\hline K & -0.2410 & -0.1784 & -0.3484 & 0.2251 & -0.3657 & 0.3415 & 0.0653 & -0.2938 & -0.1942 & 1.0000 & & & \\
\hline $\mathrm{Ca}$ & 0.1032 & -0.1035 & $-0.6087^{\star}$ & 0.0338 & $-0.5349 *$ & 0.4622 & -0.0922 & -0.4604 & 0.4973 & 0.2525 & 1.0000 & & \\
\hline $\mathrm{Mg}$ & -0.0201 & 0.3260 & $-0.5664^{*}$ & 0.0535 & -0.3922 & 0.2588 & -0.1074 & -0.3569 & $0.7433^{*}$ & -0.0418 & 0.4646 & 1.0000 & \\
\hline $\mathrm{Fe}$ & $0.7613^{\star}$ & $-0.7291^{*}$ & $-0.6349 *$ & -0.1977 & $-0.6956^{*}$ & 0.0574 & -0.3919 & $-0.7306^{*}$ & -0.0446 & 0.1981 & 0.4085 & 0.1253 & 1.00 \\
\hline $\mathrm{Cu}$ & $0.6337 *$ & -0.4306 & -0.4328 & 0.2421 & -0.4165 & 0.3456 & 0.1435 & -0.3335 & 0.4643 & 0.0314 & 0.3524 & 0.3148 & 0.66 \\
\hline Zn & $0.6320 *$ & $-0.5768^{*}$ & $-0.7501^{\star}$ & 0.1682 & $-0.6445^{\star}$ & 0.1792 & -0.2666 & $-0.6420 *$ & 0.0447 & 0.3662 & $0.5506^{*}$ & 0.3056 & $0.81^{\prime}$ \\
\hline
\end{tabular}

Note: ${ }^{*}, p<0.05$.

Table. 2 The clearance rate to and molecular weight of polysaccharides in Polygonatum sibiricum.

\begin{tabular}{|llll|}
\hline Polysaccharides & Scavenging rate $(\%)$ & Molecular weight $(\mathrm{Mw} / \mathrm{Da})$ & Molecular weight (Mn/Da) \\
\hline PCP1 & $5.61 \pm 0.98$ & 26345 & 931 \\
\hline PCP2 & $3.06 \pm 0.57$ & 51557 & 557 \\
PCP3 & $0.00 \pm 3.39$ & 177316 & 755 \\
\hline
\end{tabular}

\section{Figures}



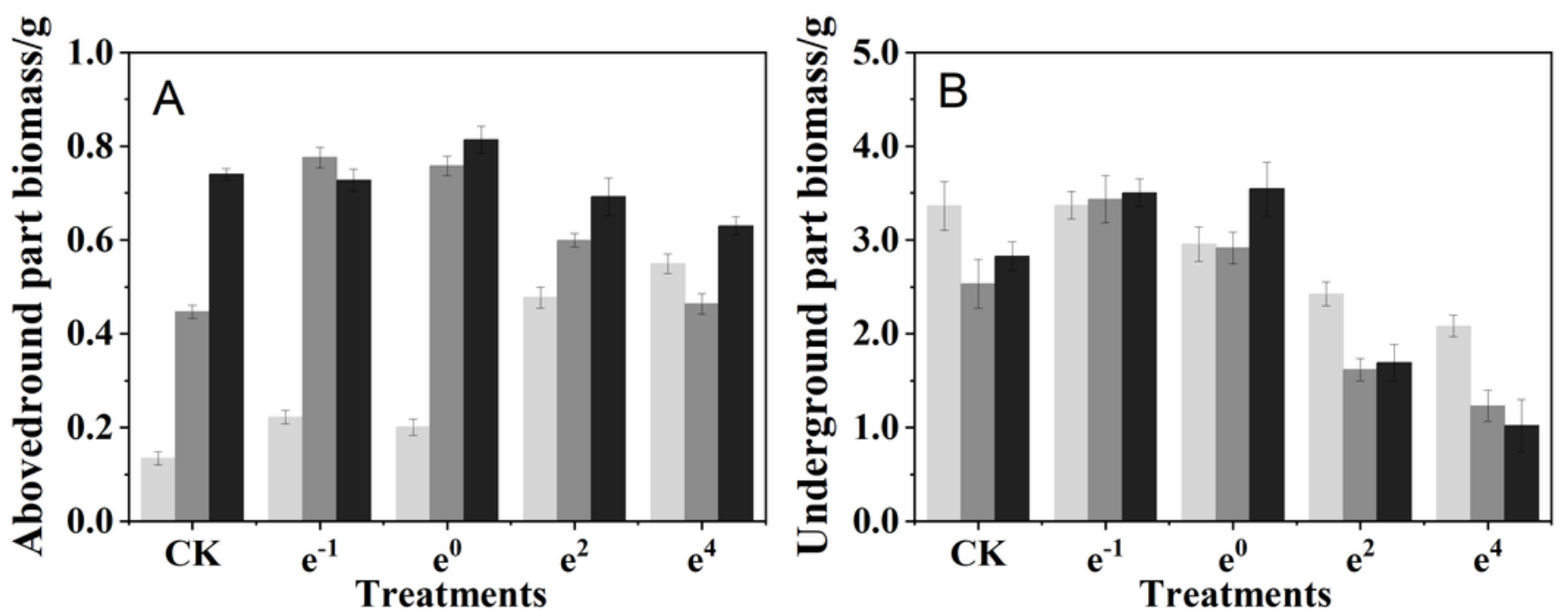

\begin{tabular}{|l|}
\hline 30 days \\
\hline 60 days \\
90 days
\end{tabular}
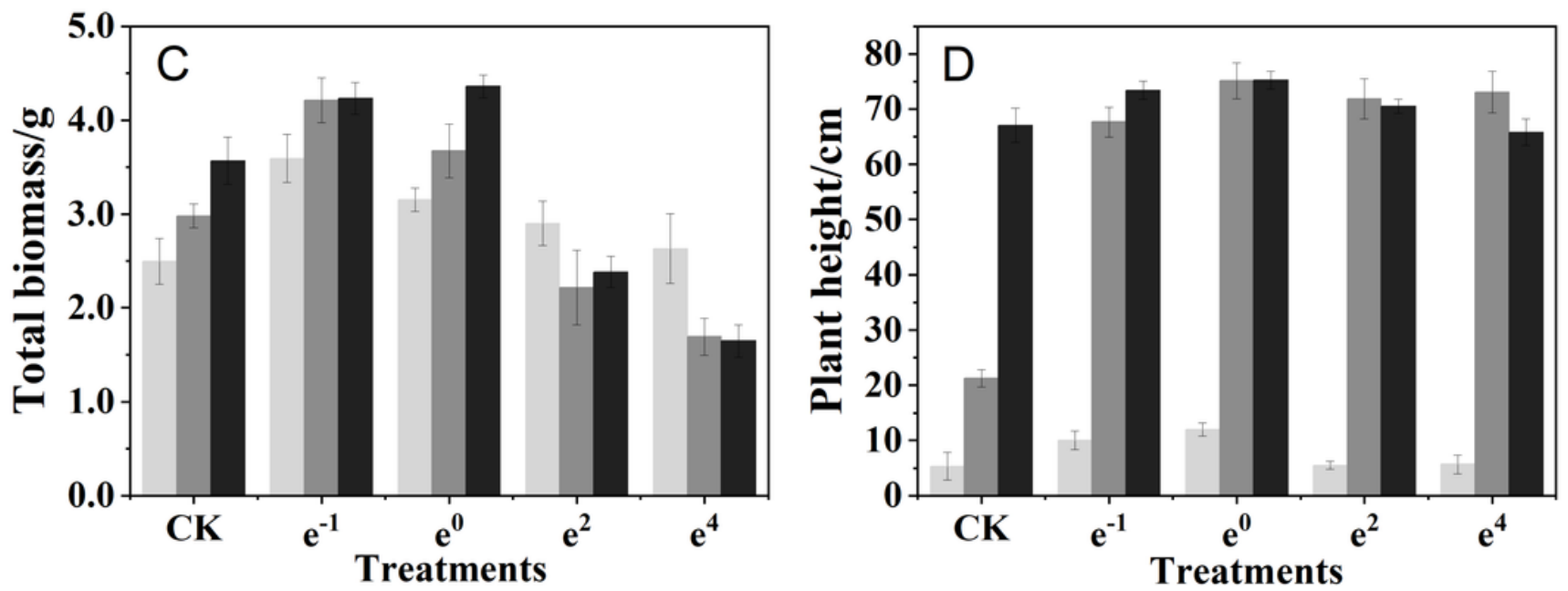

Figure 1

The biomass of Polygonatum sibiricum under different Cd stress. A, the aboveground part biomass (including roots and rhizomes), B, the underground part biomass (including stems and leaves), C, the total biomass, D, plants height 

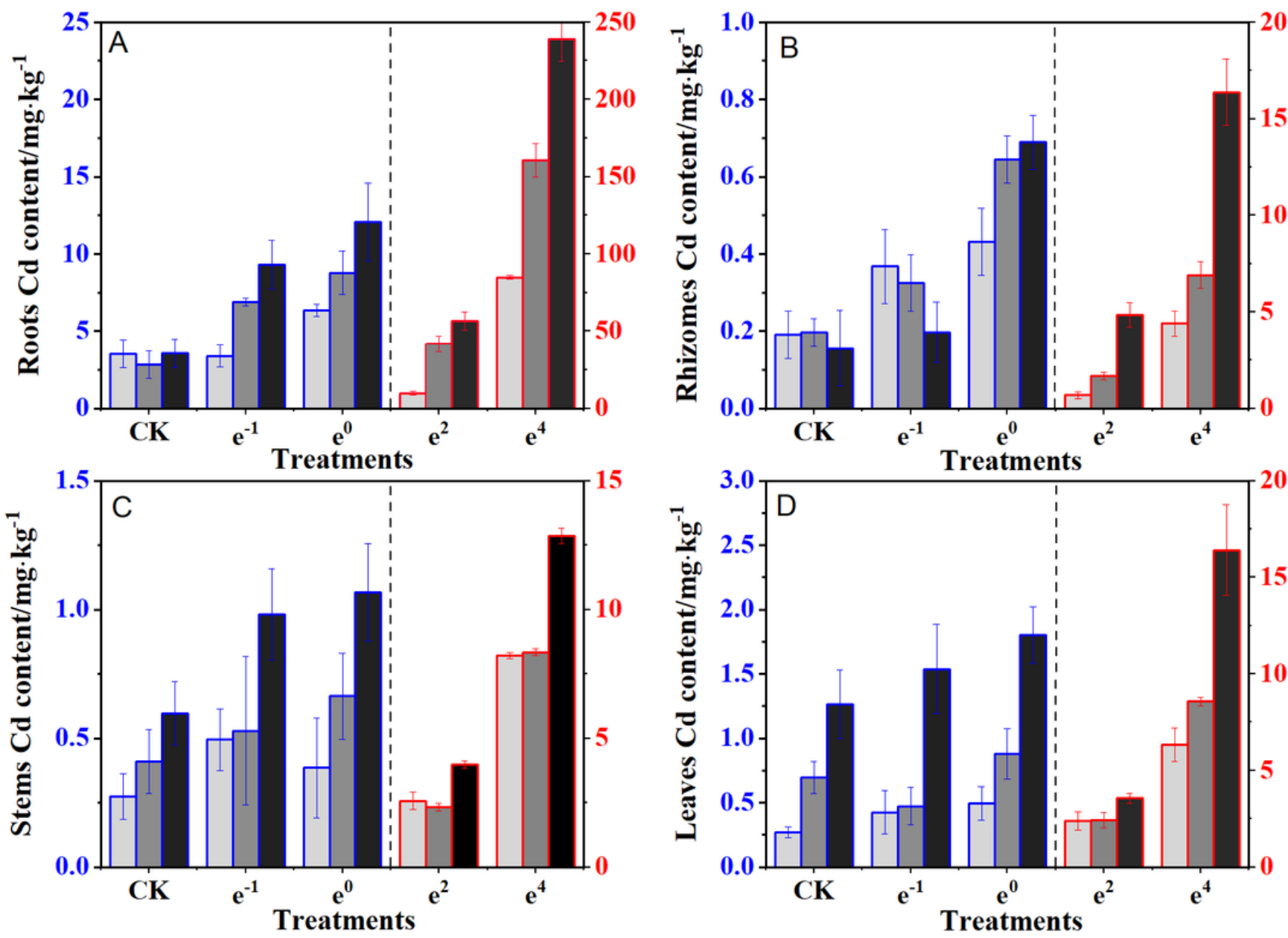

Figure 2

Cd content in roots, rhizomes, stems, and leaves of Polygonatum sibiricum. A, roots Cd content, B, rhizomes Cd content, C, stems Cd content, D, leaves Cd content. 

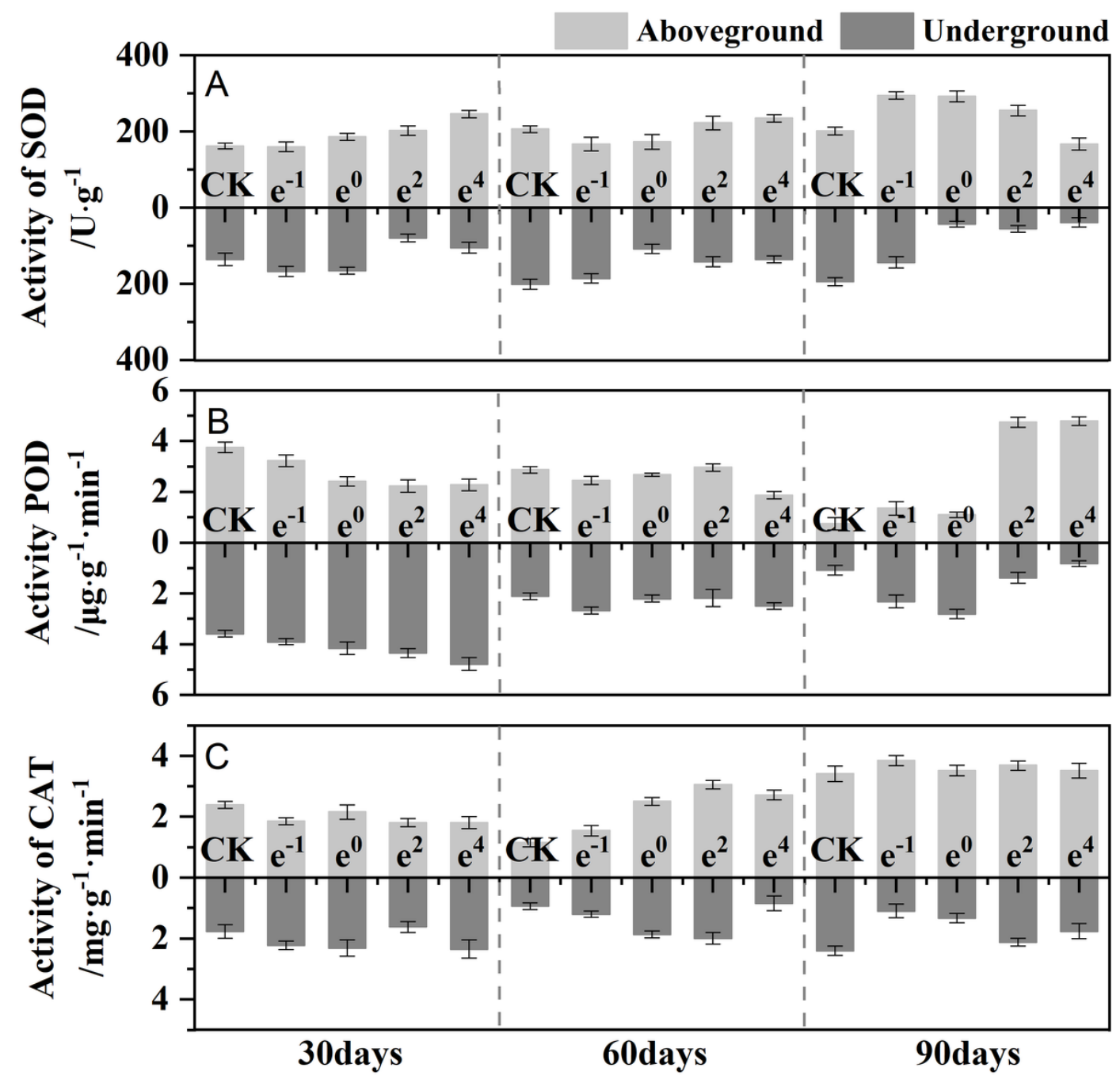

Figure 3

Antioxidant enzyme activity of Polygonatum sibiricum. A. Superoxide dismutase (SOD) activity in aboveground and underground part, B. Peroxidase (POD) activity in aboveground and underground part, C. Catalase (CAT) activity in the aboveground and underground part. 

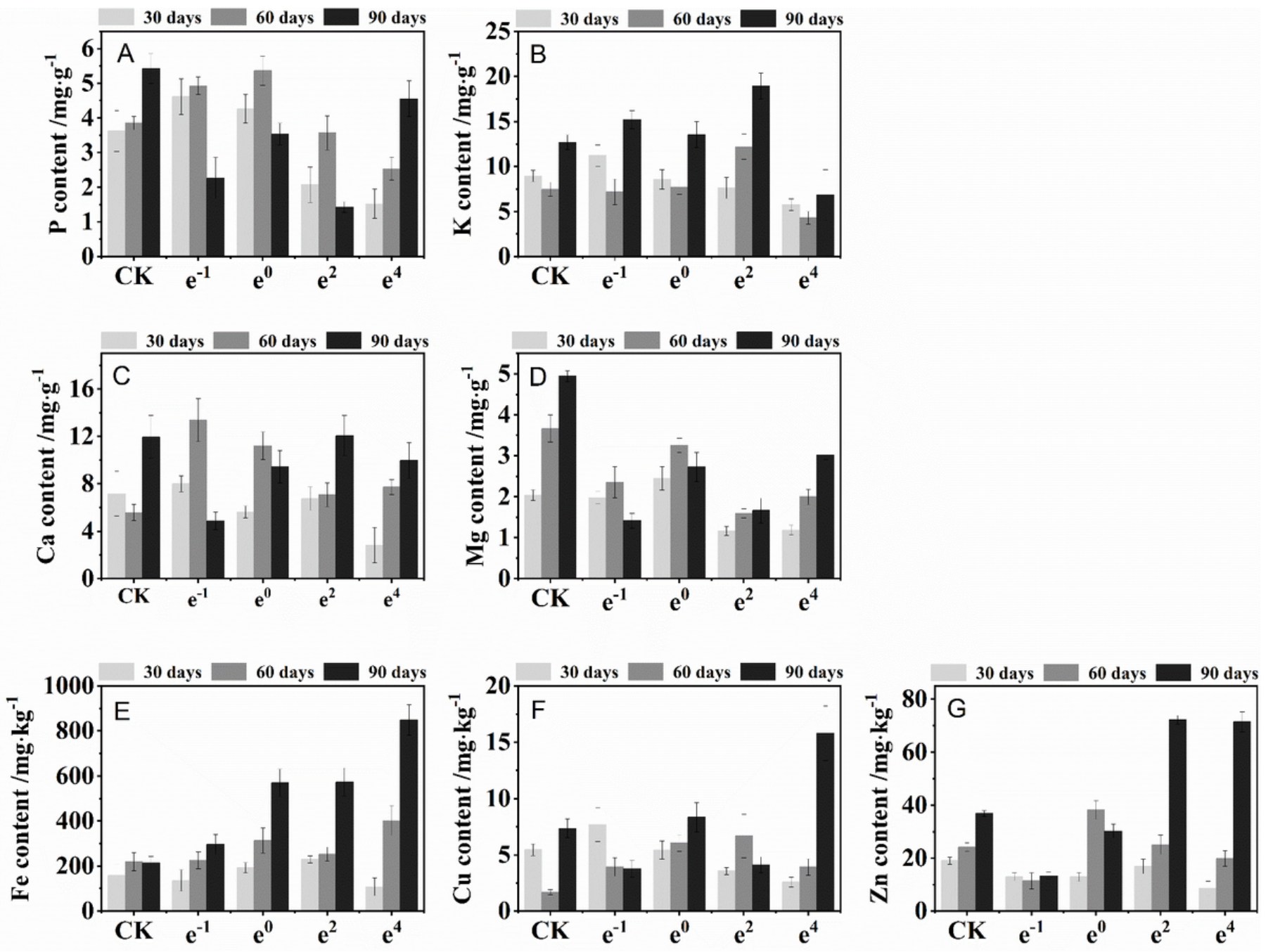

Figure 4

Changing $\mathrm{P}, \mathrm{K}, \mathrm{Ca}, \mathrm{Mg}, \mathrm{Fe}, \mathrm{Cu}$, and $\mathrm{Zn}$ content of Polygonatum sibiricum under Cd stress. A, B, C, D, E, F, and G represent P, K, Ca, Mg, Fe, Cu, and Zn, respectively.

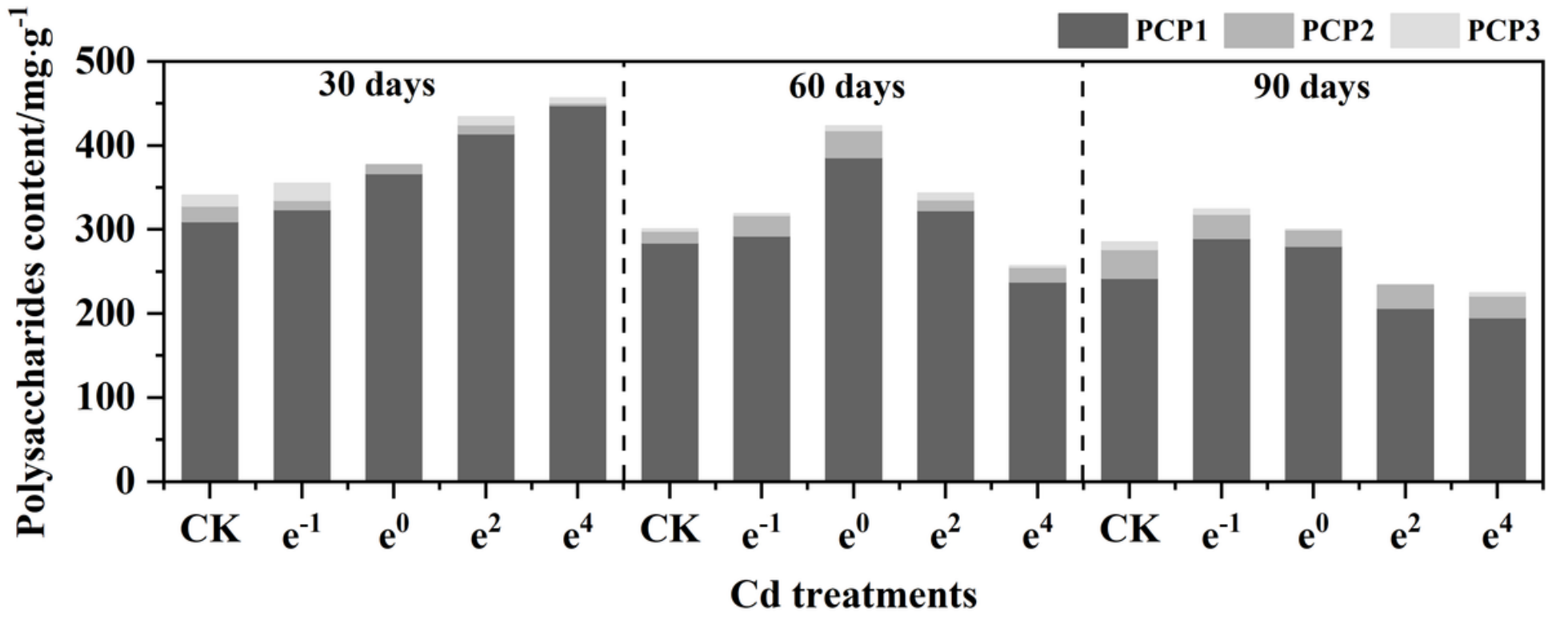

Figure 5

Polysaccharides content of Polygonatum sibiricum. PCP1: First step polysaccharides in fractionated extraction. PCP2: Second step polysaccharides in fractionated extraction. PCP3: Third step polysaccharides in fractionated extraction. 